\title{
Use Of Hydroxiapatita In The Traumatology and Orthopedics Service of the Hospital Teodoro Maldonado Carbo Iess 2005-2006
}

\author{
Dra. Tania Alvarado Chávez ${ }^{* 1}$, Dr. Marcelo Grijalva Pino ${ }^{2}$ and Dra. Beatriz Romero Varas ${ }^{3}$ \\ ${ }^{1}$ Medico Tratante de Traumatología y Ortopedia, Coordinador de Postgrado Otopedia, Docente de la Universidad Estatal de Guayaquil, IESS HTMC \\ ${ }^{2}$ Medico Residente del Hospital Universitario de Guayaquil \\ ${ }^{3}$ Medico Residente del Hospital Naval de Guayaquil
}

Submission: January 18, 2016; Published: January 31, 2017

*Corresponding author: Tania Alvarado Chávez, Medico Tratante de Traumatología y Ortopedia, Coordinador de Postgrado Otopedia, Docente de la Universidad Estatal de Guayaquil, IESS HTMC

\begin{abstract}
Hydroxyapatite is a biomaterial for bone implants with an interconnected three-dimensional structure and with a chemical composition similar to the natural inorganic support of the bone, which favors the penetrating proliferation of the tissue inside the implant and leads to the formation of interfacial chemical bonds between Both. The preclinical and clinical experience in recent years with these products has demonstrated its high biocompatibility, high capacity for tissue regeneration, perfect integration and high results, low risk of infection and absence of signs of rejection.

This biomaterial to reconstruct damaged or lost bone tissue has achieved remarkable success in specialties such as Periodontology, Maxillofacial Surgery, Orthopedics, Neurosurgery, Oncology Surgery, among others. The good results obtained with their use have solved a great problem to the Medical Sciences for many years, that is the need to restore different types of defects of bone substance. That is why this research is carried out where this material is used to repair bone defects to a group of patients at the Hospital Teodoro Maldonado Carbo (IESS), with the objectives of assessing the clinical evolution of the soft and bony tissues that cover the bone defect Treated with the porous hydroxyapatite and radiographically identifying the osteointegration of the treated bone tissue.
\end{abstract}

Keywords: Hidroxyapatite; Bone tumors; Osteoconductive; Osteoinductive

\section{Introduction}

Bone regeneration by filling (BIOMATERIALS) is a technique successfully tested and based on decades of surgical research. Continuous development of the surgical techniques, therapeutic methods and mechanical systems used in Orthopedics, Traumatology, COLUMN SURGERY, MAXILOPHYAL SURGERY and ODONTOLOGY requires an adequate location of the bone for its correct and appropriate use. Where there is no bone, it is necessary to regenerate as soon as possible. This allows both the mechanical means, which at present have achieved excellent quality, as surgical reconstruction techniques may be useful. The osteoconductive osteoconductive effect of hydroxyapatite should preferably be associated with an autologous or bone bank graft.

Determining a successful incorporation of the graft is the ability of the transplanted tissue to function just like the original tissue, maintaining its mechanical integrity and function during and after the incorporation process, and clarifying the concepts of osteoconduction and osteoinduction. In interventions on the cervical spine, both traumatic and non-traumatic injuries, the need to use grafts to replace vertebral bodies or incompetent discs is frequent. The most commonly used are those obtained from fragments of autogenous bone, iliac crest, cranial vault or ribs. Hydroxyapatite (HA) has been successfully used as an implant in spinal operations, pseudoarthrosis, trauma and infections in the last 10 years, but in Ecuador there is not much documented experience with its use in this type of surgery. Which prompted me to carry out the present research work. There are several problems with these bone grafts: they require an additional operation on the patient, with greater blood loss; There is more chance of sepsis and pain. Pelvic instability, fatigue fracture, iliac muscle hernia, fistulas, and ureteral injury may occur postoperatively, complications that may lead to delayed patient rehabilitation. 
It is for this reason that it has been experimented with the use of biocompatible and biointegral materials that are replaced by endogenous bone and among them, the calcium phosphate ceramics, which have different presentations of HA, occupy a very important place:

a. Granulated.

b. Macroporous.

c. Microporous: Small defects.

d. Blocks: For spine and pasta.

For small defects Among the traditional therapeutic methodologies we have: treatment with: bone grafts au- tologists, heterologous bone grafts, polymethylmethacrylate (bone cement), plates, prostheses, screws, etc. Currently there is an alternative that is being used infrequently but with good results, which is the adjuvant therapy with the use of hydroxyapatite bioceramics for bone defects. Which has begun to be used in the Hospital of the Ecuadorian Institute of Social Security "Dr. Teodoro Maldonado Carbo "of the city of Guayaquil for two years for a certain type of alternative therapy of bone defects.

The poor medical practice of this type of treatment and my research have led me to work for my thesis on this subject, through which I intend to support and demonstrate that this bioceramic constitutes a valid method and an excellent option in our environment as adjuvant therapy Of substitution in bone defects (surgical resections, traumatic losses, consolidation difficulty, periodontal diseases). We will be able to determine at the end of the study whether incorporation of the graft has been successful, through the notoriety of an acceptable to excellent ability of the transplanted tissue to function equal to the original tissue, after the operation, taking into account the osteoconductive and osteoinductive processes And their radiological signs (Figure 1).

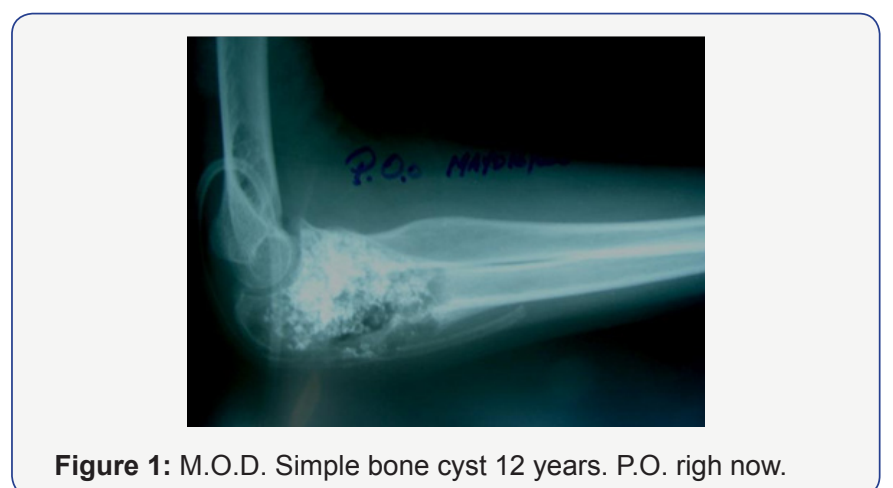

Within the field of traumatology, one of the problems to solve for the best results in the treatment of bony defects of the extremities such as benign bone tumors, pseudoarthrosis, exposed fractures, sinking fractures is to obtain that the patient With the placement of a bioimplant present an adequate clinical evolution without complications. In the field of international and national medicine, although some traditional methods have managed to obtain satisfactory results, it has been proven that over time these have not been the best, which is why this subject remains an area of medical research, Having therefore been developed some new methodologies to solve it which are currently practicing with good results for patients.

\section{Material and Method}

A descriptive, retrospective and prospective observational study of a series of cases, between January 2005 and December 2006, at the Regional Hospital II of the Ecuadorian Social Security Institute "Dr. Teodoro Maldonado Carbo ", a sample as a study base with 80 patients. Which entered by emergency and External consultation to the service of Traumatology and Orthopedics. They range in age from 10 years to 90 years of age.

For the study two processes are performed: the study process with clinical records: clinical histories, and image aids accompanied by a post-surgical radiological control process. The team is composed of the group of the Tumors and Bone Pathology module made up of specialists, residents in training and medical intern.

\section{Results}

We included data for 80 clinical records in patients who entered and were operated on in our service, in which the bioceramic (HA) of a total of 3,000 patients operated in 2 years was used as the bone substitute. 80 patients in whom Hydroxyapatite was implemented found that it was used more frequently in 48 women with a $60 \%$ percentage. In the IESS, hydroxyapatite was more frequently used in female patients aged 41-60 years, with a mean of 51 years, where 21 women were found and less frequently in male patients aged 12-40 years with an average of 26 years, where we found 7 mens. Of a total of 22 patients with benign bone tumors where hydroxyapatite was used as the most frequent we found the Enchondroma in a number of 6 patients (Figures $2 \& 3$ ).

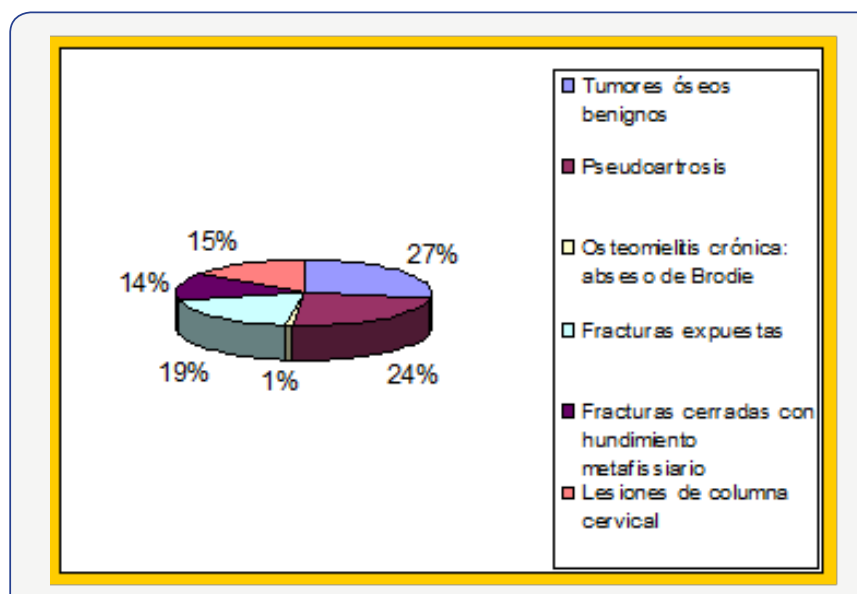

Figure 2: La distribución por patologías nos demuestra que se utilizó con mayor frecuencia hidroxiapatita en tumores óseos benignos con un total de 22 pacientes $(28 \%)$ seguidos de la pseudoartrosis con un total de 19 pacientes $(24 \%)$ y en menor frecuencia el abceso de brodie encontrado en 1 pacient. 


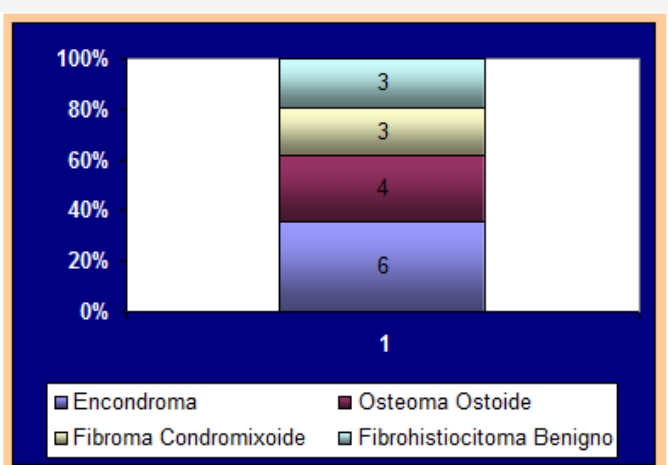

Figure 3: Pacientes con tumores oseos benignos en los que se uso H.A.

In Pseudotumoral Lesions: Simple Oseous Cyst in 2 patients as well as to the Aneurysmal Oseo Cyst in 2 patients followed by Fibrous Dysplasia in 1 patient. Of 19 patients with Pseudoarthrosis at the femur level with a total of nine patients and the humerus with 3 patients Hydroxyapatite was used in a patient with Brodie's Abdominal Patella. The distribution by Fractures Exposed in distal radius 6 patients (40\%) followed by the fibula in 5 patients (33\%) the humerus with a total of 4 patients $(27 \%)$. As for the closed fractures with metaphyseal collapse where hydroxyapatite was used, it was found that the most affected bone was the left femur and the right tibia with a total of 3 patients both and the one of less affected was the left trochanter with 1 patient. The distribution of cervical lesions shows that there was presence of spinal cord compression by cervical disc herniation in 9 patients, where hydroxyapatite was most frequently used.

The distribution in patients who used HA alone is 43 patients and $\mathrm{HA}+$ autologous bone graft 37 .

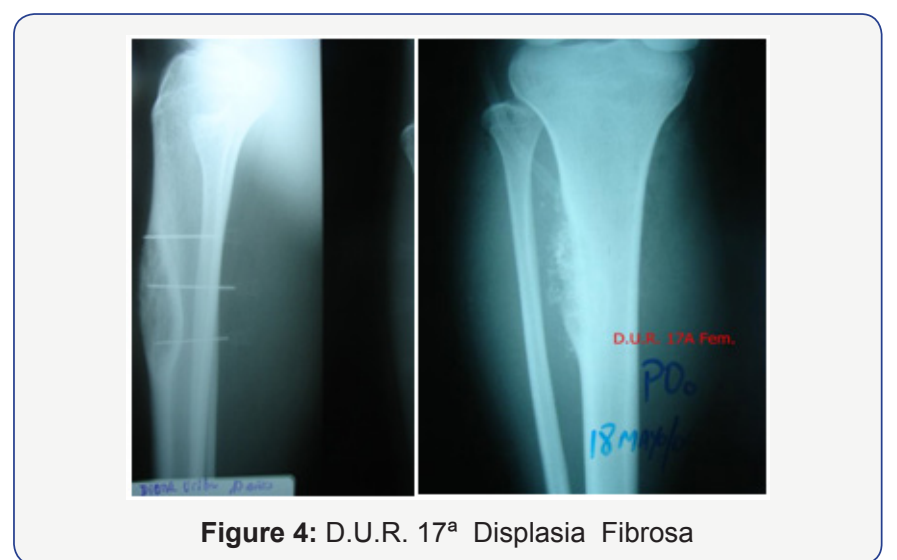

As we have found in this study, the management of the underlying pathology (benign tumors, chronic osteomilitis, pseudoarthrosis, etc.) (Figures $4 \& 5$ ) has been adequate, besides that the manipulation of the hydroxyapatite, the preparation of the receptor bed and the placement of this bioceramic were Made with the strict monitoring of the technique and it was possible to observe, there were no complications, with the use of this Biomaterial. Our results demonstrate that there were no complications such as infections, local irritation in any case due to the use of this bone substitute or adverse reactions and incompetence to the implant. The clinical behavior of the surgical wound in relation to the parameters such as pain and edema does not deserve particular mention for staying within the usual limits of any surgery.

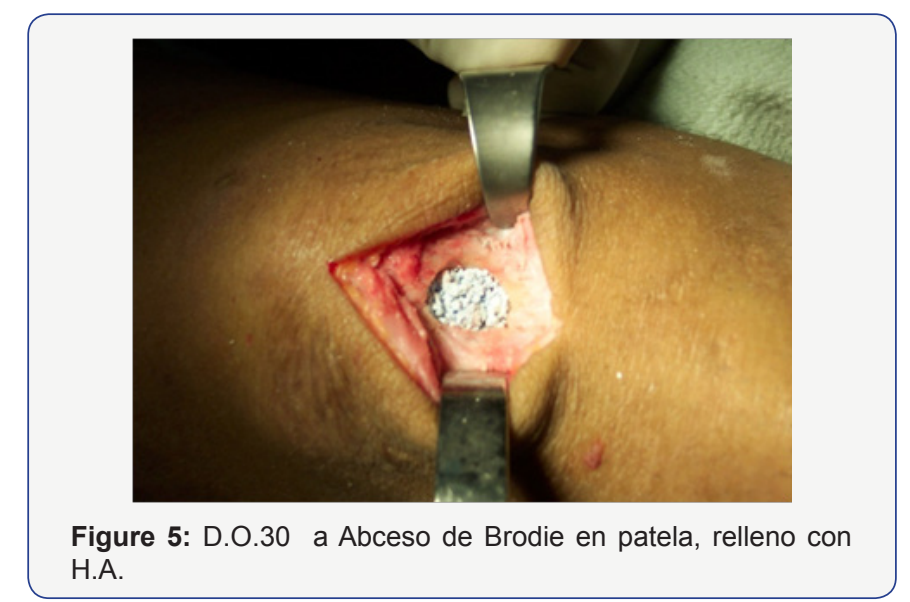

In $100 \%$ of the patients, with diagnosis of suspicion of bone tumor, biopsy samples were taken.

Regarding the final evaluation, the bone healing, the clinical recovery of the patient and the radiological results were measured as a parameter. Bone fusion was obtained by treatment in $99 \%$ of the cases. In my results combining the Hydroxyapatite + autologous bone graft we began to observe the osseointegration approximately 6 weeks in relation to the patients in which HA was used alone with a time of 3 months.

\section{Discussion}

In several bibliographies it is mentioned that a bone substitute must combine the following characteristics: an effective mechanical resistance, a minimum interference in the bone consolidation and possessing osteoconductive or osteoinductive properties. Biodegradation should be achieved without compromising local consolidation or resistance to infection. As indications of the bioimplant, as an interposition and / or filling graft, as an apposition, its use should be limited because a large amount of the biomaterial is reabsorbed by tissue fluids, since the entire surface is not in contact with bone tissue, contraindications to its use Are in sepsis of the surgical area, necrosis of the receiving area, and intra-articular implantations, because the synovial fluid favors the reabsorption of the bioimplant. The following precautions should be taken: vascularized recipient site, compressed and stable implant, HA has been shown to be a biocompatible material with excellent integration into the surrounding bone tissue, demonstrated by the high percentages of satisfactory cases of this work, having in the long term changes in its structure, obtaining tissue characteristics similar to the normal bone tissue and able to respond Equal to this before different circumstances. 
Materials, such as hydroxyapatite granules, have sufficient mechanical strength to exert support functions. They often have poor osteoconduction and, in fact, are not biodegradable. The work done so far, with the filling materials or bones that can be injected as a paste, have not been able to demonstrate the excellence of their mechanical properties, the reliability of their handling, and their biodegradability. Non-porous materials prevent recovery of the vascular system, while porous materials generally have limited strength. The combination of filler materials with osteoinductors such as BMP (growth factors: platelet concentrate) and slow release products appears to be useful in the future. The choice of the suitable filling material depends mainly on the surgical objectives to be achieved and the balance between the biological and mechanical properties required at each moment.

Some authors [1-3] say that hydroxyapatite is recognized as an osteoconductive material par excellence, somehow it exerts osteoinductive properties; Perhaps because it acts in the cellular processes through a piezoelectric effect at the expense of the presence in its composition of hydroxyl ions, responsible for an alkaline $\mathrm{pH}$ that facilitates the endochondral formation of bone.

In many cases, especially in intraarticular fractures, the surgeon is faced with the need to collect and fix the different fragments. The use of very small implants is not only extremely difficult, but also questionable [4-7]. A degradable adhesive would solve the problem if it meets the following conditions:

a. A suitable resistance in the difficult conditions of the surrounding saline environment.

b. Easy and effective application.

c. It should not interfere with consolidation while it should be biodegradable.

d. It should be biocompatible (among many other properties, not reduce local resistance to infection).

First, we would like to point out that the mean time of consolidation in our group of cases is lower than the usual average times reported by other authors [4,5,8-10] using HA + bone graft and for us this is a consequence Directly from the proven inductive effect of osteogenesis exhibited by the combined hydroxyapatite. We consider that the premature solidity of the fusion is at the expense of the porosity of the implant that allows the cellular invasion and the neoangiogénesis with rapid formation of new bone in its interior.

In addition, the non-reabsorption property of the hydroxyapatite offers additional inherent stability that avoids its breakage and when the penetrating proliferation of the neoformation fabric occurs therein significantly increases its mechanical strength in relation to the strength of the melting point when Employs homologous or autogenous bone graft, bone cement, among others. Finally we would like to emphasize that the biological activity of the implant derives from its chemical and cellular composition that induces osteogenesis (osteoinduction) and its structure that favors the growth of neoformation tissue inside (osteoconduction).

\section{Conclusion}

According to the results obtained in my study, since with the use of hydroxyapatite it contributes to fast and firm bone fusion by virtue of the proven inductive effect of osteogenesis. The need for additional surgical procedures to obtain bone grafts is avoided and, therefore, the complications that may arise from this.

The short-term and long-term results with the implantation of the biomaterial alone or associated to bone graft at the IESS hospital demonstrate that hydroxyapatite has behaved as a biocompatible material in patients by exclusively provoking a mild and early inflammatory response, with no complications Presenting a time of bone consolidation inferior to that reported by other authors; The osteoconductor by allowing the rapid formation of granulation tissue which is replaced by trabecular bone tissue both at the periphery and within the implant and also bioreabsorbable, so that it can be considered as an effective adjuvant therapy alternative for the filling of the implant [11-15]. Bone defect substitute of the bone tissue of great effectiveness and of importance in this specialty. Bone healing was achieved depending on the affected anatomic site.

The absence of an acute or chronic inflammatory reaction at the bone implant site ratifies the biocompatibility of the biomaterial, since the success of an implant is due to its entrapment in the bone through a direct bone-implant interface without inflammatory reaction.

Finally, the successes or failures are quantitatively recorded according to whether or not the lesion is healed according to the affected anatomic site (bone). Nowadays, there is a growing development of alternative procedures that aim to help problems that afflict a large population, improve the capacity for bone repair and regeneration, thus contributing to increase the quality of life and availability of patients $[16,17]$. Therefore, we concluded that hydroxyapatite possesses a group of properties (biocompatible, osteogenic, able to offer structural support, resistant to infection, easy sterilization and storage and with adequate cost-benefit ratio) that make it an effective biomaterial in Filler therapy for bone defects.

professionals which is alarming and beyond ethics. Physiotherapy should be prescribed as well as provided by physiotherapists and should be based on hard evidence (empirical). Happy to know that physiotherapists are doing higher education and engaging themselves in doctoral research.

\section{References}

1. Bruneau M, Nisolle JF, Guilliard C, Gustin T (2001) Anterior Cervical Interbody Fusion with Hydroxyapatite Graft and Plate Systems. Neurosurg Focus 10(4): E8. 
2. Patiño PR, Pérez Reyes MA, Rodríguez AC (2007) Hydroxyapatite paste. Main physical and chemical characteristics. Nova 16(6): 50912.

3. Gustilo RB, Kyle RF, Templeman DC (2005) Fractures and dislocations. T. I and II. Madrid: Mosby / Doyma Books.

4. Socarrás E (2004) Clinical evaluation of porous hydroxyapatite obtained from marine corals. Doctoral Thesis in Medical Sciences. Mexico City.

5. Blardoni F, Maestre R, Gonzalez R (2004) Coral bioimplants in othopedic. Bioceramics 11: 599.

6. Pereda Cardoso O, González R, Zayas JD, Valdés R (2005) Coral bioimplants in benign bone tumors. Rev Mxico Ortop Traumatol 9(12): $75-83$

7. Tracy DM, Doremus RH (2002) Direct electron microscopy studies fo the bone hydroxyapatite interface. J Biomed Mater Res 18(7): 719726.

8. Meseguer Olmo LR, Vicente Ortega V, Alcaraz Baños M, Galian Canovas A, Clavel-Sainz Noya M (2007) Experimental study of bone response to the implant of $\beta$-phosphate-tricalcium-collagen composite ( $\beta$-FTC-C). Pathology 28: 358-66.

9. Buck BE, González R (2005) Hidoxiapatita and its clinical application as new implantological materials in Spain. Scientific Conference of the CIMEQ. City of Madrid.
10. Pereda O (2004) Applications of hydroxyapatite as a bone implant material in Orthopedics. Biomedical 14: 22-9.

11. Pereda $O$ (2006) Bioimplants in cavitary defects (tumors, infectious traumas, pathogenesis). Rev Mexico Ortop Traumatol 13(1-2): 132-6.

12. González R, Blardoni F, Maestre H, Pereda O, Pancorbo E, et al. (2006) Lonterm results of Coralline porous hydroxyapatite HAP-200 as bone implant biomaterial in Orthopedics and Traumatology. CNIC Sciences Biol 32(2): 97-101.

13. Alvarez Cambra R (2006) Traumatic Orthopedic Surgery Treaty. T.II. Mexico City: Editorial People and Education.

14. Orozco R, Sole JM, Videla M (2005) Benign Bone Tumors. Barcelona: MASSON.

15. Ciénega MA (2005) Use of macroporous, microporous, granular and plaque hydroxyapatite as a substitute for bone grafting in Orthopedics. Rev Mex Ortop Trauma 12(5): 410-5.

16. Andrew H, Crenshaw (2004) Surgical approaches and approaches. In: Ferry S channels, publisher. Campbell orthopedic surgery. Tomo I. Madrid: Harcourt Brace, SA P. 43-7.

17. Salata LA, Craig GT, Brook IM (2006) Bone healing following the use of hydroxyapatite or isomeric bone substitutes alone or combined with a guided bone regeneration technique. Implants 13(1): 44-81.

\section{Your next submission with Juniper Publishers will reach you the below assets}

- Quality Editorial service

- Swift Peer Review

- Reprints availability

- E-prints Service

- Manuscript Podcast for convenient understanding

- Global attainment for your research

- Manuscript accessibility in different formats ( Pdf, E-pub, Full Text, Audio)

- Unceasing customer service

Track the below URL for one-step submission https://juniperpublishers.com/online-submission.php 